Rev. Adm. Saúde Vol. 17, № 69, Out. - Dez. 2017

http://dx.doi.org/10.23973/ras.69.49

ARTIGO ORIGINAL

\title{
Perspectivas de enfermeiros da rede hospitalar privada acerca da gestão de pessoas: análise da psicodinâmica do trabalho
}

Perspectives of nurses of the private hospital network on the management of people: analysis of work psychodynamics

\author{
Gímerson Erick Ferreira1, Edemilson Pichek dos Santos², Érica Rosalba \\ Mallmann Duarte ${ }^{3}$, Antonio Carlos Silva Costa ${ }^{4}$
}

1 Administrador. Enfermeiro. Mestre e doutorando pelo Programa de Pós-Graduação em Enfermagem da Universidade Federal do Rio Grande do Sul (PPGENF-UFRGS). Professor assistente do Curso de Enfermagem das Faculdades Integradas de Taquara - FACCAT.

2 Acadêmico de enfermagem da FACCAT e bolsista de iniciação científica

3 Enfermeira. Doutora em engenharia da produção. Professora adjunta da Escola de Enfermagem da UFRGS e do Programa de Pós-Graduação em Saúde Coletiva (PPGCOL).

4 Cientista social. Professor titular da Faculdade de Economia, Administração e Contábeis da Universidade Federal de Alagoas (UFAL)

\section{RESUMO}

O presente estudo é fruto do projeto matricial intitulado Gestão de pessoas em saúde: relações entre organização do trabalho e saúde mental à luz das clínicas do trabalho. Trata-se de um estudo qualitativo, que objetivou analisar as demandas do trabalho do enfermeiro na rede hospitalar privada, a partir das vivências de enfermeiros de um hospital alagoano. Utilizou-se o referencial teórico a Psicodinâmica do Trabalho. Os dados foram coletados por meio de entrevistas com 16 enfermeiros. A partir da análise dos dados emergiram três categorias temáticas as quais sugerem que estar "sempre acima das expectativas" retrata o contexto de trabalho do enfermeiro de hospital privado na contemporaneidade, o qual se configura como imaterial e é gerador de sofrimento. $O$ estudo sinaliza a necessidade de investimentos da gestão hospitalar para este trabalhador, no sentido de propiciar 
fontes de elaboração e transformação do sofrimento, em situações prazerosas no trabalho.

Palavras-chave: trabalho, sofrimento psíquico, serviço hospitalar de enfermagem, gestão de pessoas

\begin{abstract}
The present study is the result of a matrix project, entitled Management of people in health: relations between work organization and mental health in the light of work clinics. This is a qualitative study that aimed to analyze the demands of nurses 'work in the private hospital network, based on nurses' experiences of a hospital in Alagoas. We used the theoretical reference to the Psychodynamics of Work. The data were collected through interviews with 16 nurses. From the analysis of the data emerged three thematic categories which suggest that being "always above expectations" portrays the work context of the private hospital nurse in contemporaneity, which is configured as immaterial and generates suffering. The study indicates the need for investments of hospital management for this worker, in order to provide sources of elaboration and transformation of suffering, in pleasurable situations at work.
\end{abstract}

Keywords: work, psychological stress, nursing service, hospital, personnel management

\title{
INTRODUÇÃO
}

Nos últimos anos, o mundo do trabalho tem sido marcado por contínuas transformações, a exemplo da globalização, dos avanços tecnológicos, da reestruturação produtiva e dos novos modelos de gestão, os quais implicam na reordenação das práticas do trabalho, assim como nos seus sentidos, natureza, conteúdos e significados. Vivencia-se atualmente um período em que coexistem diversos modelos de produção, e que gradativamente vêm substituindo o trabalho de produção material pelo trabalho dito imaterial, conhecido também por capital intelectual, cujos padrões clássicos de medida não mais se aplicam e as formas de saber passam a ser revalorizadas, exigindo um investimento de si mesmo ao incorporar esse saber ${ }^{1}$.

Entende-se por trabalho imaterial "o conjunto de atividades corporais, intelectuais, criativas, afetivas e comunicativas inerentes ao trabalhador, atualmente valorizadas e demandadas como condição indispensável à produção"2:4 e que dele resultam produtos intangíveis, a exemplo de sentimentos de confiança, segurança, envolvimento afetivo, cuidados e conforto aos clientes, numa relação produçãoconsumo $^{2,3}$. O trabalho de enfermagem no cenário hospitalar configura-se sob tais premissas, visto que há uma forte tendência histórica de seus profissionais a doarem-se, para suprir as exigências básicas da profissão. 
Este cenário tem como característica principal sua complexidade, visto que incorpora avanços constantes em termos de ciência e tecnologia, e que demandam do enfermeiro a articulação da dimensão gerencial e assistencial nas ações que desenvolvem em prol do gerenciamento do cuidado. Para gerenciar o cuidado, o enfermeiro precisa adaptar constantemente o seu processo de trabalho, lançando mão de competências que o permita tomar decisões assertivas, e que situem o usuário como eixo central de suas ações ${ }^{4}$. Tal condição remete à tipificação de um modelo profissional específico, proativo, coerente às propostas do cenário contemporâneo, o qual esteja alinhado aos objetivos, metas e desenvolvimento institucional, e que vise em seus processos a otimização dos recursos e a melhoria contínua das práticas que desenvolve ${ }^{5}$.

Entretanto, estes profissionais, assim como os demais trabalhadores da enfermagem, tipicamente organizam seu trabalho a partir de modelos flexíveis, em meio à precariedade e à produção intensa, sendo submetidos a elevadas cargas de trabalho e a exigências de tempo integral e polivalência. Este contexto favorece um quadro de dedicação ilimitada ao trabalho, que, de maneira sutil, estabelece relações, compromissos e engajamentos institucionais que, para além do reconhecimento e do prazer no trabalho, fomentam a cultura do lucro, da produção e da competitividade acirrada, intensificando o capitalismo em sua forma atual ${ }^{3}$.

Os novos tempos passam a ser caracterizados pelo movimento, pela fluidez e pela flexibilidade, e com elas, novas formas de conceber e estruturar o trabalho em enfermagem passam a ser criadas, fazendo-se notar uma intensa imaterialização dos seus processos. Ao mesmo tempo, as organizações de saúde requerem novos modelos de gestão e gerência do cuidado, sendo necessário que os enfermeiros extrapolem os limites institucionalizados do cuidado tradicional, e invistam na elaboração de estratégias coerentes com um contexto que demanda continuamente formas diferenciadas de compartilhamento de decisões ${ }^{6}$.

Nesse ritmo, as práticas de gestão contemporâneas, baseadas nesta ideologia, promovem a necessidade de um investimento ambíguo do enfermeiro para atender às demandas do trabalho, que por um lado sustenta a imagem de profissional zeloso e proativo, e por outro, fomenta a concepção de que é preciso suportar as adversidades do trabalho como uma forma de conquista. Tais configurações interferem de modo determinante nos modos de trabalhar e de viver destes profissionais, uma vez que o trabalho em saúde possui especificidades que se devem principalmente ao seu caráter interativo e que lhe conferem uma racionalidade técnica própria e distinta da produção material, cuja atividade está ligada à subjetividade humana, característica do trabalho imaterial ${ }^{7}$.

Sob este enfoque, o trabalho imaterial assume importante valorização na produção e fornecimento de serviços de saúde e de enfermagem, assumindo, aparentemente, a condição flexível e autônoma tão almejada pelas categorias profissionais. No entanto, ao tempo em que o trabalho imaterial anuncia liberdades ampliadas pela diminuição da alienação do trabalho, das fronteiras e dos meios de confinamento, apregoa outras formas de controle e servidão que extrapolam as antigas formas de poder $^{2}$, uma vez que pode estar atrelado à mobilização subjetiva dos trabalhadores, ao buscar respostas às novas exigências que são demandadas no trabalho contemporâneo. 
Diante do exposto, considera-se o modo como o enfermeiro desenvolve seu trabalho na contemporaneidade como potencialmente delicado, uma vez que as novas exigências do mundo do trabalho, embora demandem um trabalhador mais flexível, "autônomo", responsável e com maior poder para tomar decisões; o faz assumir riscos constantes frente à produção, e assim vive sob o império do medo, devendo identificar-se e modelar-se aos objetivos traçados pela instituição e por ele mesmo em prol da sua carreira. Tais pressupostos encontram ancoragem epistemológica na teoria de Christophe Dejours, a psicodinâmica do trabalho, cujo foco central está nas ações empreendidas e vivenciadas por trabalhadores e que são geradoras de prazer e sofrimento no trabalho; bem como nas estratégias construídas e desenvolvidas pelos trabalhadores para confrontar a organização do trabalho ${ }^{8}$.

Face ao exposto, apresentou-se como pertinente a seguinte questão de pesquisa: como os modos de trabalhar dos enfermeiros de hospitais privados ilustram o trabalho imaterial na contemporaneidade? Ao se propor como objetivo de investigação: analisar as vivências e demandas de enfermeiros hospitalares na contemporaneidade; buscou-se uma possível contribuição para ampliar a compreensão acerca dos modelos de gestão contemporâneos e do modo como estes vêm sendo utilizados nas organizações hospitalares, especialmente no contexto de trabalho do enfermeiro.

\section{METODOLOGIA}

Tratou-se de um estudo exploratório, de abordagem qualitativa, realizado em uma instituição hospitalar de natureza privada de Maceió, AL, no período entre setembro de 2011 e fevereiro de 2012 . Os dados foram coletados mediante entrevistas semiestruturadas com 16 enfermeiros que atuam neste hospital, dos quais, 13 são do sexo feminino, lotados em todos os turnos de trabalho. A idade dos participantes variou entre 23 e 58 anos; o tempo na profissão, de um a 16 anos; e o trabalho no hospital atual entre seis meses e nove anos.

A entrevista foi conduzida por um instrumento que almejava conhecer a percepção destes acerca da expectativa de seus empregadores em relação ao trabalho do enfermeiro, e que ações estes profissionais precisaram empreender para atender às demandas solicitadas por seus empregadores. Os participantes foram selecionados intencionalmente entre os profissionais, de acordo as suas disponibilidades e aceitação em participar do estudo. As entrevistas foram realizadas no respectivo local de trabalho, mediante agendamento prévio e em local apropriado, respeitando a privacidade dos envolvidos. Adotaram-se como critérios de inclusão: atuar no hospital há pelo menos seis meses, e estar em atividades no período de coleta de dados; e de exclusão, enfermeiros afastados por motivos de quaisquer naturezas. $O$ critério de saturação foi adotado para a definição da população participante, dando por encerrada a coleta de dados ao identificar a repetição sistemática das falas.

As prerrogativas éticas foram atendidas, sendo utilizado o Termo de Consentimento Livre e Esclarecido, onde foram registradas as autorizações para as gravações das entrevistas em áudio, e firmado a garantia do anonimato dos sujeitos. O projeto de pesquisa foi avaliado e aprovado pelo Comitê de Ética em Pesquisa da Universidade 
Federal de Alagoas, apresentando parecer favorável à sua execução, conforme protocolo 011742-2010-91.

As informações procedentes da coleta foram reunidas, organizadas e analisadas com base no conjunto de instrumentos metodológicos da análise de conteúdo temática ${ }^{9}$, seguindo as etapas de pré-análise, exploração do conteúdo e tratamento dos resultados e interpretação, originando os conjuntos interpretativos relacionados aos modos de trabalhar e de viver do enfermeiro hospitalar frente às demandas da contemporaneidade.

A apresentação dos resultados deu-se a partir dos conjuntos interpretativos mais significativos, sendo classificados com a letra "E" os trechos das entrevistas escolhidos para exemplificar e significar a discussão, seguidos do algarismo arábico que representa a ordem em que as entrevistas foram transcritas. A análise das verbalizações permitiu a organização das falas por aproximação, em núcleos de sentido, os quais foram agrupados em três categorias: "configurações do trabalho do enfermeiro no âmbito hospitalar", "modos de gerir o trabalho frente às demandas do cenário hospitalar" e "relações entre saúde, adoecimento e trabalho no contexto do enfermeiro hospitalar", as quais estão descritas no próximo tópico.

\section{RESULTADOS E DISCUSSÃO}

As verbalizações dos participantes permitiram identificar situações do cotidiano do enfermeiro de hospital privado que delineiam a organização do trabalho deste profissional no cenário investigado. Neste âmbito, e em meio às demandas deste contexto, mobilizam-se e encontram modos de gerir seu trabalho que são geradoras de prazer e sofrimento no trabalho.

\section{Configurações do trabalho do enfermeiro no âmbito hospitalar privado}

O enfermeiro, no âmbito hospitalar privado, desenvolve ações gerenciais em prol de melhorias no cuidado e da qualidade do serviço prestado pela instituição. Nesse ritmo, as ações empreendidas por este profissional demandam planejamento, tomada de decisão, acompanhamento e controle das ações de enfermagem, com vistas à otimização dos recursos que são dispensados. Os enfermeiros têm a percepção de que a expectativa do empregador é de que as atividades prescritas, não só sejam executadas em sua efetividade, como também, superem as suas expectativas. As seguintes verbalizações manifestam tais entendimentos:

A expectativa deles [empregadores] [...] é que eu esteja sempre acima das expectativas. (E-02)

O enfermeiro precisa dar conta da organização do serviço, ele gerencia, ele assiste, e ainda acaba assumindo coisas que não é da sua alçada. (E16) 
Eu sei que a empresa [hospital] quer que eu seja proativa, que eu não deixe aparecer os problemas, que eu evite o desperdício de material, que controle isto e aquilo [...] cada dia é uma coisa nova. (E-06)

Os enfermeiros entendem que a expectativa do empregador é que estes sejam proativos e que estejam sempre acima das expectativas. Tal entendimento corrobora os resultados de estudo desenvolvido em hospital acreditado do sul do Brasil ${ }^{5}$, em que foi evidenciado que o gerenciamento proativo do enfermeiro é considerado importante fator estratégico ao desempenho organizacional, por atuarem no controle ativo e preventivo de eventos adversos que garantam a efetividade da assistência do paciente e a otimização dos recursos. As perspectivas assinalam a divisão do trabalho, os ritmos, tempos e exigências que são requeridos do enfermeiro de hospitais da rede privada, sugeridas pelos seguintes dados:

O dia passa muito depressa, e quando paro, vejo que ainda falta evoluir paciente, prescrever, e já se foi o plantão. (E-05)

As mudanças aqui acontecem num piscar de olhos, e eu preciso estar sempre "antenada", principalmente porque trabalho na rede privada. (E08)

O enfermeiro tem que ser polivalente, porque ele faz de tudo em pouco, assume tudo no serviço [...] toma decisões o tempo todo [...] ele precisa ser um gerente ambulante, pois a maioria das suas demandas é inesperada. (E-16)

A gente sabe que hoje em dia não pode parar, então no meu tempo livre eu faço o possível para estudar, faço cursos, faço pós-graduação, é uma forma de investir em mim, investir na minha profissão. (E-01)

Tais perspectivas vão ao encontro da literatura contemporânea acerca dos modos de organização do trabalho, na qual evidencia-se que esta conjuntura impõe exigências diversas aos seus trabalhadores, incluindo cadências, rapidez, aprendizagem, informação, adaptação às expectativas organizacionais e exigências do mercado, características do trabalho imaterial ${ }^{2,10}$. Regidos por tais cadências, os modos de trabalhar e de ser de enfermeiros de hospitais privados, são revestidos por ideais do mundo do trabalho contemporâneo, assumindo configurações líquidas ${ }^{11}$, sendo guiados por uma cultura gerencialista, que, em nome da melhor performance, sutilmente os obrigam a serem empreendedores de si mesmos.

As dificuldades relatadas por estes enfermeiros expõem o ritmo de trabalho intenso e a sobrecarga a que estes profissionais submetem-se, uma vez que estão a todo instante sendo cobrados por resultados e metas que nem sempre se limitam à tarefa para a qual foram destinados. O trabalho prescrito, na perspectiva da psicodinâmica do trabalho, é a ponta visível de um iceberg, no qual se encontra submersa uma parte que é invisível, não prescrita, por vezes não reconhecida e que transgrede a prescrição ${ }^{12}$.

Esta condição explicita o distanciamento entre aquilo que é prescrito e o que é real no trabalho, sendo a realidade do trabalho muito complexa, pois foge às regras, e impõe a necessidade de sobressair-se frente a uma série de possibilidades além das 
descritas pela prescrição para que se torne exequível, a exemplo de imprevistos, falhas, contradições e ineditismo ${ }^{8}$. O que se pôde observar nesta categoria, em que estão presentes os modos como o enfermeiro organiza o seu trabalho no âmbito institucional privado, é que há grandes divergências entre o trabalho que lhe é prescrito e o trabalho que lhe é imposto pela realidade de um hospital, marcada pela diversidade de pessoas e relações (com a equipe de saúde, com a gestão, com os usuários e familiares, com os demais membros da equipe de enfermagem). Os enfermeiros definem o seu trabalho como sendo composto por atividades que, embora inseridas sempre em contextos de interação com essas pessoas, deve portar-se como os "olhos da instituição", definido por eles como alguém que deve sempre fidelidade à instituição, conforme as verbalizações a seguir:

Tenho que seguir ordens... Então, mesmo sabendo que eu poderia fazer, às vezes dói o coração, mas eu preciso negar. (E-09)

Eu acabo sendo os olhos da instituição, porque eles [empregadores] esperam sempre de mim, que eu cobre, que eu estimule, que eu brigue, que eu controle... então os técnicos e os pacientes, meio que já esperam isso de mim. (E-03)

É equipe médica, aí vem a nutrição, depois vem os chefes, paciente, familiares... Olha, não é fácil, você sofre pressão de todos os lados, e precisa lidar com todos eles. (E-06)

As relações entre os pares, de forma geral, soam como superficiais, com pouca mobilização coletiva para lidar com os entraves cotidianos, embora este seja o responsável por coordenar de forma cooperativa os trabalhadores para complementar a prescrição do trabalho ${ }^{13}$. Os modos de trabalhar do enfermeiro abordam características de um cenário hospitalar da rede privada, marcadas pela polivalência, pelo individualismo e pela necessidade de estar sempre acima das expectativas. Estas características associam-se à pressão pelo sempre mais, pelo foco nos resultados e pela busca de altos níveis de performance, causando a ideia de que não é permitido ao enfermeiro, em determinadas situações, ser humano, reagir ou se manifestar afetivamente com sua rede de relações.

\section{Modos de gerir o trabalho frente às demandas do cenário hospitalar}

Na compreensão da psicodinâmica do trabalho, trabalhar consiste em acrescentar algo de si às prescrições quando elas não funcionam, processo que ocorre mediante mobilização dos esforços subjetivos para confrontar os impasses do trabalho e alcançar a resolução dos impasses ${ }^{8,14}$. Essa mobilização coloca em ação um tipo particular de inteligência, denominada inteligência prática ou criativa, que consiste em agir de maneira astuciosa e com liberdade em relação às normas, visando a eficácia das ações ${ }^{8}$. Nessa categoria, foram apreendidos os núcleos de sentido que retratam as manifestações de mobilização de esforços empreendidas por estes profissionais, e, consequentemente, os modos de colocar em ação a inteligência prática: 
Nunca é o bastante, sempre há algo para melhorar. Por mais que me empenhe no meu serviço, sempre fica a sensação de que você poderia ter sido melhor, que poderia fazer algo a mais pelo paciente. (E-12)

É muito bom o sentimento de ajudar o outro, de poder aliviar de algum modo o sofrimento de uma pessoa que está com dor, que estava na pior (E-01).

No trabalho hospitalar, o enfermeiro é cerceado pelos modos de trabalhar contemporâneos, em que as especificidades do seu fazer estão relacionadas a tarefas imateriais, as quais exigem dedicação significativa, num movimento de entrega de corpo e alma para a organização ${ }^{3}$. As verbalizações remetem a algo que foi aceito e assimilado pelos próprios enfermeiros, demonstrando que não só as organizações esperam que estes estejam sempre além das expectativas, como também, estes mesmos vivem em um movimento constante de autocontrole e engajamento, acreditando nunca serem suficientemente efetivos.

Nesse ritmo de adesão e incorporação aos novos modos de trabalhar, cada trabalhador mais parece seu próprio patrão, contribuindo para que o poder das organizações não encontre limites ${ }^{15}$. Assim, comumente, assumem e incorporam como seus, os objetivos e metas institucionais, confundido a concepção de cuidado integral e a postura histórica de doação e sacrifício, que é fonte de realização pessoal e profissional, com a obrigação de fazer acontecer, de empreender e de assumir riscos, mesmo sem condições favoráveis a este desenvolvimento.

Os enfermeiros demonstraram ainda uma postura de aceitação e de aparente imobilismo frente às demandas deste cenário no contemporâneo, podendo esta conduta ser interpretada como estratégia defensiva adotada para lidar com tais imposições. Em determinados momentos, expressam certa modulação de suas competências em prol do trabalho e do que é exigido pela instituição privada, o que faz com que, muitas vezes, tenham atitudes contrárias às suas filosofias, em função do emprego:

Eu até gostaria de me dedicar mais à assistência direta ao paciente, mas a prioridade aqui é que eu fique mais restrita à gerência, pois as maiores cobranças aqui são com relação aos gastos. Somos cobrados o tempo todo. (E-08)

Todos sofrem pressão aqui, mas com tanta coisa para fazer, eu queria que o relógio tivesse umas duas horas a mais para dar conta de tudo. Então tem coisas que eu prefiro deixar assim mesmo e priorizar aquilo que realmente sou cobrada. (E-03)

Dessa maneira, percebe-se que a decisão dos enfermeiros inseridos neste contexto, embuste-se, silenciosamente, numa aparente omissão, pois preferem executar o que thes parece provocar menor dano. Situação semelhante foi evidenciada em pesquisa com profissionais de enfermagem de hospital universitário do sul do Brasi $^{16}$, o qual constatou que estes profissionais acreditam ser menos penoso acatar ordens e obedecer ao instituído, seguindo o que determina a organização, a executar o que lhes parece mais corretos e expressa uma forma de resistência ética e transformadora ${ }^{13}$. Infelizmente, a opção de alguns profissionais de enfermagem 
pode recair no imobilismo e na ausência de construção de estratégias de resistência, o que, não só reduz o exercício de poder da categoria, como contribui para a intensificação da invisibilidade da profissão na área da saúde ${ }^{16}$.

Por outro lado, para alcançar os objetivos e seguir à risca as prescrições, os enfermeiros admitem que, em determinadas situações, são impelidos a fazer uso de artimanhas e estratégias "fraudulentas" que os constrangem, por desrespeitar as regras, ou por agir contra a ideologia para o qual foram preparados. Esta situação, entretanto, demonstrou certa ambivalência em sua análise, pois, ao mesmo tempo em que se percebem incitados a agir de maneira a burlar o sistema, sentem-se recompensados por recorrer à sua criatividade, à inteligência astuciosa, promovendo todo um sentido pessoal do que faz:

Tem muita coisa que eu não concordo, que eu sei que é errado, e que eu aprendi que não deveria ser assim, mas o que posso fazer?... A gente precisa dar um jeito, precisa resolver. (E-09)

Falam-me o tempo todo que sou inovadora, criativa, porque querendo ou não, a gente sempre dá um jeito em tudo (E-06)

Algumas vezes é preciso resolver um problema que você sabe que é o certo para aquela ocasião, só que você fica com tanto medo... não chega a ser culpa, porque você fez a coisa certa, mas na cabeça deles não, porque o certo é fazer a coisa que está escrita. (E-15)

Eu me sinto a pior das criaturas por ter que economizar num curativo, ou dizer não tem, sabendo que tem, ou que não posso fazer, sabendo que posso, mas tenho que dizer por que o paciente é atendido pelo SUS, só que algumas vezes me finjo de louco e faço. (E-13)

A mobilização subjetiva é identificada quando, burlando as normas, os enfermeiros empregam sua criatividade e o melhor de si, na tentativa de resolver os entraves em seu trabalho. Esse processo é potencializado a partir do reconhecimento dos pares, que consideram uma das enfermeiras do hospital criativa e inovadora, uma vez que a mesma consegue "dar jeito em tudo".

Ante tais situações, o enfermeiro acaba fazendo o prescrito, apesar de não concordar com ele, tendo que, muitas vezes, burlar as normas para garantir a eficácia de suas ações. Exemplo claro de inteligência astuciosa está expresso no relato do enfermeiro que se recusa a negar à realização de um procedimento para o paciente sem condições financeiras, demonstrando a incompatibilidade entre as ordens prescritas da gestão e as exigências morais deste profissional. Mobilização semelhante é evidenciada em outros estudos, os quais revelam que rotineiramente nos serviços de saúde, os profissionais vivenciam situações desafiadoras em que precisam agir em contradição a seus preceitos éticos, e que não só comprometem a qualidade do trabalho, como pode ser um disparador de sofrimento moral ${ }^{16,17}$.

\section{Relações entre saúde, adoecimento e trabalho no contexto do enfermeiro hospitalar}


Nesta categoria, analisam-se situações de prazer e sofrimento vivenciadas pelos enfermeiros do hospital investigado, e que anunciam condições de saúde e riscos de adoecimento no trabalho. No contexto investigado, observou-se que as configurações do trabalho do enfermeiro, bem como as manifestações de mobilização deste profissional, incidem diretamente na disposição psíquica deste profissional, que, angustiado, elabora processos defensivos para minimizar o sofrimento.

É uma loucura mesmo, porque a gente se vê viciado em café, em cafeína, para suportar o ritmo de dois empregos, aí quando chega em casa, que pode descansar, a gente não dorme, então tenho que tomar algo para dormir. (E-11)

Depois de um longo dia de trabalho, é natural ficar mais irritado, sem paciência [...] você acaba descontando em quem está perto de você. (E-02)

A gente come muito aqui, é algo que sempre acontece, pedir pizza, sanduíche, especialmente na madrugada. (E-06)

Situações encaradas com naturalidade pelos enfermeiros deste estudo, podem esconder em seus interstícios sintomas e patologias mal compreendidas e diagnosticadas incorretamente, pois constituem mecanismos para lidar com o sofrimento no trabalho. Manifestações como estas, e que anunciam o uso regular de cafeínas e derivados para manter-se acordado, ou mesmo de tranquilizantes para dormir, modificações dos hábitos alimentares, e alterações de comportamento, com aumento da irritabilidade, da angústia e da ansiedade; sinalizam uma infinidade de patologias que podem estar associadas ao trabalho. Estudo recente evidenciou que a maioria dos enfermeiros de um serviço hospitalar de emergência apresentavam sintomas de depressão ${ }^{18}$, estando os principais fatores para o adoecimento relacionados à sobrecarga e desvalorização no trabalho, e à falta de recursos. Contudo, mesmo apresentando quadro depressivo, a maioria destes enfermeiros não percebia o próprio sofrimento psíquico e nem se sentiam adoecidos.

Esta condição é comumente observada no cotidiano das práticas de saúde, em que, dificilmente os profissionais de saúde conseguem estabelecer nexos entre trabalho, saúde e adoecimento em sua anamnese, não relacionando as queixas inespecíficas dos pacientes ao trabalho. Isso reforça a necessidade e a importância da escuta clínica nos espaços de promoção da saúde e nos diferentes contextos institucionais, visto a centralidade do trabalho na contemporaneidade, pois muitos trabalhadores adoecem por não encontrarem em seu ambiente de trabalho, espaços de fala e escuta em que possam enfrentar e transformar o sofrimento.

No contexto de trabalho observado, situações de angústia e medo são manifestadas pelos enfermeiros em virtude, especialmente, da insegurança nos postos de trabalho, e que expõem o receio destes de perder o emprego. Tais condições são fortes impulsionadores do sofrimento e da baixa vivência de prazer, e, quando não elaborados, ampliam os riscos de adoecimento em virtude do trabalho. A literatura mostra que tal condição repercute sobre a identidade e a saúde mental do trabalhador, exigindo que este esteja atento às formas de operar no trabalho e, 
portanto, aos modos de "ser" trabalhador de enfermagem ${ }^{19}$, e de modelar-se continuamente para acompanhar as exigências de um cenário de mudanças ${ }^{20}$.

O que posso fazer? Eu preciso desse emprego! Se hoje saio dele, tem outros dez querendo o meu lugar! (E-11)

A luta agora é para manter-se empregado! Então se eu sei que a empresa quer assim, então você não escolha. (E-14)

Se eu fosse concursada, ainda cabia questionar alguma coisa [...]. Mas ainda não desisti, estou sempre tentando os concursos que aparecem. (E16)

Eu gostaria de ter mais liberdade no meu trabalho, vou conseguir isso um dia, mas por enquanto vivo disto, morro de medo de sair daqui! (E-09)

Nesse ritmo, cada indivíduo deve sentir-se responsável por seus resultados, como exigência para desenvolver suas competências e talentos, e mesmo se percebendo injustiçado ou sobrecarregado, a exigência permanece, pois é ele quem precisa se adaptar ao tempo da empresa e não o inverso. O trabalhador passa a responsabilizar-se pelo seu desempenho e também pelas consequências dele decorrentes, seguindo a lógica da gestão de $\mathrm{si}^{15}$, onde, aquele que não atender às atuais demandas do trabalho, poderá a vir ocupar a condição de refugo humano ${ }^{11}$.

Esse cenário aponta para sentimentos de medo, insegurança e frustração, frequentes na vida do trabalhador contemporâneo, que sofre uma pressão intensa pela busca da eficiência. Nesse sentido, os enfermeiros demonstram estar sempre com "um pé atrás", e assumem os seus medos diante da possibilidade de perder o posto ou de se tornar obsoleto.

\section{CONCLUSÕES}

Os resultados do presente estudo sugerem que os modos de trabalhar e de ser de enfermeiros de hospitais da rede privada apresentam características do trabalho imaterial e podem interferir nos modos como conduzem suas vidas, visto que se caracterizam pela polivalência e necessidade de modulação constante. Isto porque, estes profissionais estão submetidos a uma dinâmica que os impõe ritmos frenéticos, aumento gradativo das cadências e intensas cobranças.

Esta condição, aliada à sensação de insegurança e condições de incerteza, assume potencial de imobilização, pois, face à angústia e sofrimento de ter que conviver com o medo constante do desemprego, tornam-se cada vez mais proativos, na tentativa de estarem "sempre acima das expectativas". Esta é a expressão que vêm ilustrando os atuais modos de trabalhar dos enfermeiros neste cenário, e que, ao tempo em que os convida a serem empreendedores de si, seduzindo-os para um engajamento sem precedentes, também os coloca em situação de sofrimento psíquico, e adoecimento, mesmo que estes não se deem conta.

Esta condição é preocupante, pois, na medida em que o enfermeiro é levado a aderir um comprometimento compatível com as regras da competitividade e da 
empregabilidade, e a trabalhar em prol da mera manutenção no mercado de trabalho, revela a imagem de um trabalhador alienado e acrítico, por vezes incapaz de aprofundar a reflexão acerca do que o faz sofrer, e de expressar um posicionamento emancipatório ao visualizar os diversos fatores que geram sofrimento.

O recorte feito por este estudo não esgota a possibilidade de análise do trabalho do enfermeiro na contemporaneidade, entretanto, reitera-se que estudos nesta perspectiva possam auxiliar no preenchimento de lacunas epistemológicas importantes no conhecimento em saúde e enfermagem, permitindo ampliar o olhar e a escuta aos fenômenos ligados a esta temática.

\section{REFERÊNCIAS}

1. Gorz A. O imaterial: conhecimento, valor e capital. São Paulo: Annablume; 2005.

2. Grisci CLI. Trabalho imaterial, controle rizomático e subjetividade no novo paradigma tecnológico. RAE-eletrônica. [Internet]. 2008 [citado 2017 ago. 10]; 7(1): Art. 4. Disponível em: http://www.redalyc.org/html/2051/205114657005/

3. Traesel ES, Merlo ARC. Trabalho imaterial no contexto da enfermagem hospitalar: vivências coletivas dos trabalhadores na perspectiva da Psicodinâmica do Trabalho. Rev. bras. saúde ocup. [Internet]. 2011 [citado 2017 ago. 10]; 36 (123): 40-55. Disponível em: http://www.redalyc.org/html/1005/100518631005/.

4. Almeida MDLD, Segui MLZH, Maftum MA, Labronici LM, Peres AM. Instrumentos gerenciais utilizados na tomada de decisão do enfermeiro no contexto hospitalar. Texto contexto - enferm. [Internet]. 2011 [citado 2017 ago. 10]; 20 (n.spe): 131-7. Disponível em: http://www.scielo.br/pdf/tce/v20nspe/v20nspea17.

5. Ferreira GE, Dall'Agnol CM, Porto AR. Repercussões da proatividade no gerenciamento do cuidado: Percepções de enfermeiros. Esc. Anna Nery. [Internet]. 2016 [citado 2017 ago. 10]; 20(3). Disponível em:

http://www.scielo.br/pdf/ean/v20n3/1414-8145-ean-20-03-20160057.pdf

6. Santos JLG, Pestana AL, Guerrero, P, Meirelles BSH, Erdmann AL. Práticas de enfermeiros na gerência do cuidado em enfermagem e saúde: revisão integrativa. Rev. bras. enferm. [Internet]. 2013 [citado 2017 ago. 10]; 66(2): 257-63. Disponível em: http://www.scielo.br/scielo.php?script=sci_arttext\&pid=S003471672013000200016

7. Carvalho BG, Peduzzi M, Mandú ENT, Ayres JRCM. Work and Inter-subjectivity: a theoretical refection on its dialectics in the field of health and nursing. Rev. LatinoAm. Enfermagem. [Internet]. 2012 [citado 2017 ago. 10]; 20(1):[08 telas]. Disponível em: http://dx.doi.org/10.1590/S0104-11692012000100004.

8. Dejours C. A loucura do trabalho: estudo de psicopatologia do trabalho. 6. ed. São Paulo: Cortez; 2015. 
9. Minayo MCS. O desafio do conhecimento: pesquisa qualitativa em saúde. 14 ed. Petrópolis: Vozes; 2014.

10. Campos JF, David HSL. Avaliação do contexto de trabalho em terapia intensiva sob o olhar da psicodinâmica do trabalho. Rev. esc. enferm. USP. [Internet]. 2011 [citado 2017 ago. 10]; 45(2): 363-8. Disponível em: http://www.scielo.br/pdf/reeusp/v45n2/v45n2a08.

11. Bauman, Z. Vida líquida. 2. ed. Rio de Janeiro: Jorge Zahar; 2009.

12. Mendes AM, Facas EP. Transgressão do trabalho prescrito como estratégia para transformar o sofrimento - estudo da inteligência prática. In: Mendes AM, Merlo ARC, Morrone CF, Facas EP. Psicodinâmica e clínica do trabalho: temas, interfaces e casos brasileiros. Curitiba: Juruá; 2012.

13. Dejours C, Abdoucheli E, Jayet C. Psicodinâmica do trabalho. São Paulo: Atlas; 2011.

14. Dejours C. Trabalho vivo: trabalho e emancipação. Brasília, Paralelo 15; 2012.

15. Gaulejac, V. Gestão como doença social. Aparecida: Idéias \& letras; 2007.

16. Barlem EL, Lunardi VL, Lunardi GL, Tomaschewski-Barlem JG, Silveira RS.

Sofrimento moral no cotidiano da enfermagem: traços ocultos de poder e resistência. Rev. Latino-Am. Enfermagem. [Internet]. 2013 [citado 2017 ago. 10]; 21(1): [08 telas]. Disponível em: http://www.scielo.br/pdf/rlae/v21n1/pt_v21n1a02.pdf

17. Cardoso CML, Pereira MO, Moreira DA, Tibões HBB, Ramos FRS, Brito MJ Menezes. Sofrimento Moral na Estratégia de Saúde da Família: vivências desveladas no cotidiano. Rev. esc. enferm. USP. [Internet]. 2016 [citado 2017 ago. 10]; 50(n. esp): 089-095. Disponível em: http://www.scielo.br/pdf/reeusp/v50nspe/pt_0080-6234-reeusp-50-esp-0089.pdf

18. Oliveira FP, Mazzaia C, Marcolan JF. Sintomas de depressão e fatores intervenientes entre enfermeiros de serviço hospitalar de emergência. Acta paul. enferm. [Internet]. 2015 [citado 2017 ago. 10]; 28(3): 209-15. Disponível em: http://www.scielo.br/scielo.php?pid=S010321002015000300209\&script=sci_abstract\&tlng=pt

19. Dal Pai D, Lautert L, Krug JS. Psicodinâmica e saúde mental do trabalhador de enfermagem: ritmo acelerado e intensificação do fazer. Enfermagem em Foco. [Internet]. 2011 [citado 2017 ago. 10]; 2(1):38-43. Disponível em: https://doi.org/10.21675/2357-707X.2011.v2.n1.72.

20. Malagutti W, Miranda SMRC. Os caminhos da enfermagem: de Florence à globalização. Enfermagem em Foco. [Internet]. 2011 [citado 2017 ago. 10]; 2(supl):85-88. Disponível em: https://doi.org/10.21675/2357-707X.2011.v2.nSUP.90. 
Recebido: 08 outubro 2017. Publicado: 01 novembro 2017

Correspondência: Gímerson Erick Ferreira. E-mail: gimersonferreira@faccat.br

Conflito de interesses: os autores declararam não haver conflito de interesses 